\title{
Renal Biopsy in Children-Effect on Treatment Decisions: A Single-Center Experience: Correspondence
}

\author{
Suprita Kalra ${ }^{1}$ (D)
}

Received: 15 September 2021 / Accepted: 18 November 2021 / Published online: 14 January 2022

(c) Dr. K C Chaudhuri Foundation 2021

To the Editor: We read with interest the original article by Pilania et al. entitled "Renal Biopsy in Children-Effect on Treatment Decisions: A Single-Center Experience" [1] and would like to compliment the authors on their efforts in trying to bring forth the importance of kidney biopsy in children with various glomerular disorders. It is especially important, as brought forth very succinctly in the paper, in children with AKI and nephrotic syndrome with atypical features who can have very similar clinical presentation initially, and correct histopathological diagnosis is crucial for appropriate management. We would, however, like to put forth following comments for further clarification/consideration from a clinicians perspective:

1. It would have been helpful if the authors had attempted the histopathological correlation of the atypical features in children with nephrotic syndrome, which prompted them to do an early kidney biopsy, especially in the subset of patients with nonminimal change disease (MCD) who are more likely to present with atypical features like gross or microscopic hematuria, hypertension, etc., and their management is based chiefly on the underlying histopathological diagnosis [2].

2. Also it would have been helpful if the authors had elaborated on the children in whom electron microscopic (EM) picture of biopsies helped clinch the clinical diag- nosis or contributed to making the correct diagnosis significantly. This is especially important as still in many cases in our country, EM is missed due to nonavailability or high costs involved but has been shown to have management as well as prognostic implications [3].

\section{Declarations}

Conflict of Interest None.

\section{References}

1. Pilania RK, Venkatesh GV, Nada R, et al. Renal biopsy in children-effect on treatment decisions: a single-center experience. Indian J Pediatr. 2021;88:1036-9.

2. Alshami A, Roshan A, Catapang M, et al. Indications for kidney biopsy in idiopathic childhood nephrotic syndrome. Pediatr Nephrol. 2017;32:1897-905.

3. Zhang X, Xu J, Xiao H, et al. Value of electron microscopy in the pathological diagnosis of native kidney biopsies in children. Pediatr Nephrol. 2020;35:2285-95.

Publisher's Note Springer Nature remains neutral with regard to jurisdictional claims in published maps and institutional affiliations.
Suprita Kalra

kalrasuprita@gmail.com

1 Department of Pediatrics, Army Hospital Research \& Referral, New Delhi 110010, India 